\title{
Assessment of nutritional status of school going girls (7-9 years) residing in shelter homes of Udaipur city
}

\author{
Umang Nigam, Sarla Lakhawat and Geetika Sharma
}

\begin{abstract}
The present study was conducted with the objective to assess and compare the nutritional status of school going girls (7-9 years) residing in government and non-government shelter homes in Udaipur city (Rajasthan) and to impart nutrition education to the workers and assess their gain in knowledge. A comprehensive list of shelter homes was obtained from Department of social welfare. One twenty school going girls ( 60 girls each from Government and non-government shelter home) of age 7-9 years were selected.The data was collected by using questionnaire technique and analyzed using frequency, per cent, mean per cent score and paired t-test. Information was collected on general profile, anthropometric measurement, clinical assessment, dietary assessment (24 hours recall method) and nutritional knowledge of workers among shelter home. Among both the shelter homes (28.33\%),(39.16\%) and (32.5\%) girls were in the age of 7,8 and 9 years. The mean height, weight and BMI of school going girls were, significantly $(\mathrm{P}<0.05)$ lower than their respective standard values in both the shelter homes. According to Gomez classification (18.33\%) girls among non-government shelter home and $(6.66 \%)$ girls in government shelter home were malnourished in the age of 8 years. According to BMI for age z- score of WHO (2006), (44.16\%) of the respondents were in normal and (30.83\%) of respondents were in severe undernutrition range. Clinical findings indicates that 11.66 per cent of respondents suffered from lack of luster in hair, 9.16 per cent suffered from pale conjunctiva and 11.66 per cent suffered from cheilosis among both the shelter homes. As per haemoglobin estimation majority of girls were anaemic in the age of 8 and 9 years. The intake of pulses, roots and tubes, other vegetable, green leafy vegetables, sugar and jaggery and fats and oils were significantly $(\mathrm{P}<0.05)$ lower than RDI except milk and milk products were found non-significant in both shelter homes. The intake of protein, fats, $\beta$ - carotene, iron, riboflavin, niacin, Vitamin- $\mathrm{C}$ and carbohydrates content was significantly $(\mathrm{P}<\mathrm{O} .05)$ lower than respective RDA except the intake of Energy, Thiamine and Calcium were found non-significant in both shelter homes.
\end{abstract}

Key Words : Anthropometric measurements, Malnutrition, Recommended dietary intake, Recommended dietary allowances

How to cite this article : Nigam, Umang, Lakhawat, Sarla and Sharma, Geetika (2018). Assessment of nutritional status of school going girls (7-9 years) residing in shelter homes of Udaipur city. Food Sci. Res. J., 9(1): 26-32, DOI : 10.15740/HAS/FSRJ/9.1/26-32. 